Subscriber access provided by King Abdullah University of Science and Technology Library

\title{
Letter
}

\section{Giant Photoluminescence Enhancement in CsPbCl3 Perovskite Nanocrystals by Simultaneous Dual-Surface Passivation}

Ghada H. Ahmed, Jehad K. El-Demellawi, Jun Yin, Jun Pan, DHINESH BABU VELUSAMY, Mohamed Nejib Hedhili, Erkki Alarousu, Osman M. Bakr, Husam N. Alshareef, and Omar F. Mohammed

ACS Energy Lett., Just Accepted Manuscript • DOI: 10.1021/acsenergylett.8b01441 • Publication Date (Web): 31 Aug 2018

Downloaded from http://pubs.acs.org on September 5, 2018

\section{Just Accepted}

"Just Accepted" manuscripts have been peer-reviewed and accepted for publication. They are posted online prior to technical editing, formatting for publication and author proofing. The American Chemical Society provides "Just Accepted" as a service to the research community to expedite the dissemination of scientific material as soon as possible after acceptance. "Just Accepted" manuscripts appear in full in PDF format accompanied by an HTML abstract. "Just Accepted" manuscripts have been fully peer reviewed, but should not be considered the official version of record. They are citable by the Digital Object Identifier (DOI@). "Just Accepted" is an optional service offered to authors. Therefore, the "Just Accepted" Web site may not include all articles that will be published in the journal. After a manuscript is technically edited and formatted, it will be removed from the "Just Accepted" Web site and published as an ASAP article. Note that technical editing may introduce minor changes to the manuscript text and/or graphics which could affect content, and all legal disclaimers and ethical guidelines that apply to the journal pertain. ACS cannot be held responsible for errors or consequences arising from the use of information contained in these "Just Accepted" manuscripts. 


\title{
Giant Photoluminescence Enhancement in $\mathrm{CsPbCl}_{3}$
}

\section{Perovskite Nanocrystals by Simultaneous Dual-Surface}

\author{
Passivation
}

Ghada H. Ahmed ${ }^{\dagger}$, Jehad K. El-Demellawit, Jun Yin', Jun Pan', Dhinesh Babu Velusamy', Mohamed

Nejib Hedhili ${ }^{\Psi}$ Erkki Alarousu', Osman M. Bakrt, Husam N. Alshareef $f^{\dagger}$ and Omar F. Mohammed ${ }^{*}$

${ }^{\dagger}$ King Abdullah University of Science and Technology (KAUST), Division of Physical Sciences and Engineering, Thuwal 23955-6900, Kingdom of Saudi Arabia

${ }^{Y}$ King Abdullah University of Science and Technology (KAUST), Core Labs, Thuwal, 23955-6900, Saudi Arabia

AUTHOR INFORMATION

Corresponding Author

*Email: omar.abdelsaboor@kaust.edu.sa 


\begin{abstract}
The presence of localized trap states on the surface of $\mathrm{CsPbCl}_{3}$ perovskite nanocrystals $(\mathrm{NCs})$ is one of the greatest challenges precluding the development of optoelectronic applications of these NCs. Passivation of these defect sites provides a promising pathway to remediating their electronic and optical properties, such as photoluminescence quantum yield (PLQY). Herein, we demonstrate a post-synthetic dual-surface treatment using trivalent metal ion salts, i.e., $\mathrm{YCl}_{3}$, as a new passivation approach that enhances the PLQY up to $60 \%$ while preserving the NC size and crystal structure. Such remarkable enhancement of the PLQY along with prolongation of the average PL lifetimes of treated NC samples indicates effective passivation of the surface defects and subsequent suppression of the formation of surface non-radiative recombination centers. As a segue towards optoelectronic applications, we probed the photoelectric performance of the $\mathrm{NCs}$ using ultra-flexible devices; we found that $\mathrm{YCl}_{3}$-treated $\mathrm{CsPbl}_{3} \mathrm{NC}$ films exhibit an order of magnitude larger photocurrent compared to their non-treated counterparts. Our experimental and theoretical results provide an insightful understanding of the effective passivating roles of $\mathrm{Y}^{3+}$ and $\mathrm{Cl}^{-}$ions on the surface of $\mathrm{CsPbCl}_{3} \mathrm{NCs}$, as well as offers a new path to synthesize high-quality NCs for UV-light conversion applications.
\end{abstract}

\title{
TOC GRAPHICS
}

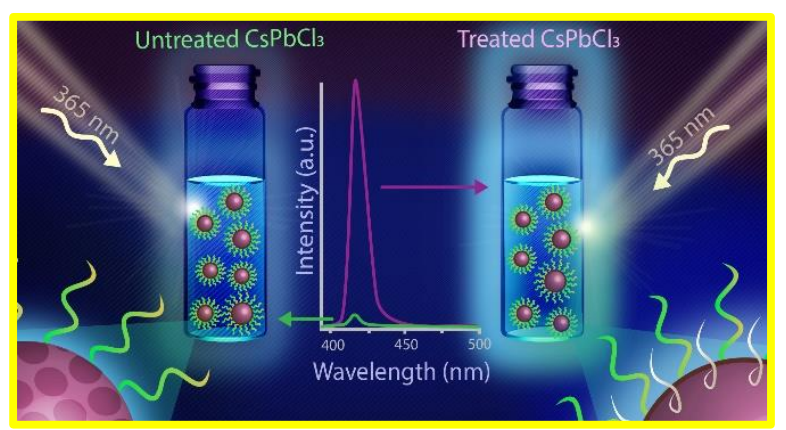


Inorganic cesium lead halide $\mathrm{CsPbX}_{3}(\mathrm{X}=\mathrm{Cl}, \mathrm{Br}, \mathrm{I})$ perovskite nanocrystals (NCs) have recently attracted great attention as a promising new class of luminophores that offers substantial improvements in optoelectronic applications such as light-emitting diodes (LEDs) $)^{1-4}$, lasers ${ }^{5-7}$, waveguides ${ }^{8}$ and photodetectors. $^{9-15}$ This is due to their extraordinary photo-physical properties, including high photoluminescence quantum yields (PLQY) with narrow emission bandwidths, wide color gamut and highly tunable bandgaps throughout the ultraviolet, visible, and near-infrared spectra controlled by halide-ion substitution, different dimensionality and compound stoichiometry. ${ }^{1-2,16-26}$

Unlike conventional semiconductor NCs (i.e., CdSe, InP), the soft ionic crystalline structure of lead-halide perovskites show a high defect-tolerance. ${ }^{27-29}$ This paramount feature can be rationalized as being due to the location of the defect energy levels of perovskite NCs within the valence band (VB) or conduction band (CB) rather than the bandgap itself. Still, the presence of typical defects such as undesirable cation or anion vacancies tends to have energy states that fall within the $\mathrm{CB}$ and VB, leading to a significant loss in radiative carrier recombination. ${ }^{27-28}$ Colloidally synthesized $\mathrm{CsPbBr}_{3}$ and $\mathrm{CsPbI}_{3}$ NCs are highly luminescent in the green and red spectral regions; their PLQY is close to unity. ${ }^{16-17,30-31}$ In sharp contrast, extremely low PLQY is reported for $\mathrm{CsPbl}_{3} \mathrm{NCs}$, which could possibly result from the presence of different types of structure defects (such as chloride vacancy) at the surface of the NCs. ${ }^{32-35}$

Post-synthetic surface passivation has been demonstrated to be an effective method that introduces surface functionalities and removes the defect points on the NC surfaces. Post-synthetic surface treatment of $\mathrm{CsPbBr}_{3}$ and $\mathrm{CsPbI}_{3} \mathrm{NCs}$ has been widely investigated with the aim to boost the PLQY near to unity using a range of organic and inorganic salts such as thiocyanate salts ${ }^{30}$, lead bromide salt ${ }^{16}$, $\mathrm{DDAB}^{36-37}$, or even bidentate chelating agents such as IDA. ${ }^{17}$ However, for the surface modification of 


\begin{abstract}
$\mathrm{CsPbl}_{3} \mathrm{NCs}$, to the best of our knowledge, only tetrafluoroborate salts have been applied to the surface of $\mathrm{CsPbCl}_{3} \mathrm{NCs}$, showing a notable enhancement in the PLQY of $\mathrm{CsPbCl}_{3} \mathrm{NCs}$ of up to $50 \%{ }^{38}$
\end{abstract}

In this work, we explore the dual-surface passivation of $\mathrm{CsPbCl}_{3} \mathrm{NCs}$ using trivalent metalchloride salts, i.e., $\mathrm{YCl}_{3}$. We conducted several optical and structural characterization as well as density functional theory (DFT) calculations to understand the role of $\mathrm{YCl}_{3}$ on the surface stability and optical performance. The steady-state spectroscopic results show remarkable increase in the PLQY, from $1 \%$ to $60 \%$, while maintaining the shape, size and crystal structure. We demonstrate that $\mathrm{Y}^{3+}$ and $\mathrm{Cl}^{-}$ions efficiently occupy the surface $\mathrm{Pb}-\mathrm{Cl}$ ion vacancies, enriching the density of states in the $\mathrm{CB}$ without creating any mid-gap states based on the DFT results. In addition, we probe the photoresponse of two

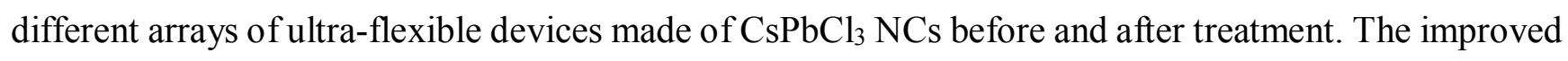
device performance of the treated NCs vs the non-treated ones, correlates very well with the aforementioned results in terms of effectiveness of surface passivation.

To study and decipher the effect of the surface passivation, transmission electron microscopy (TEM) measurements were performed. According to the HRTEM images and the size-distribution histograms (Figure $1 \mathrm{a}-\mathrm{d}$ ), both the pristine and the $\mathrm{YCl}_{3}$-treated samples are highly crystalline in structure, present regular cubic shape morphologies with narrow size distributions and nearly the same average diameter of $9 \pm 0.7 \mathrm{~nm}$ and $9.4 \pm 0.6 \mathrm{~nm}$ for the untreated and treated sample (insets (a,c)), respectively. The high-resolution TEM (HR-TEM) images (Figure $1(b, d))$ also show the same interplanar distance of $0.38 \mathrm{~nm}$ for both pristine and treated NCs with clear lattice fringes corresponding to the inter-planar distance of the (110) crystal plane for the cubic phase of $\mathrm{CsPbCl}_{3} \mathrm{NCs}^{1,}{ }^{13}$ Also, the crystal structures of the as-synthesized $\mathrm{CsPbCl}_{3}$ samples were investigated using X-ray diffraction (XRD), Figure S1. According to the XRD patterns, both pristine and treated NCs possess a cubic crystalline perovskite structure. Also, the peak positions remain unchanged after treatment indicating no 
structural changes occurred upon treatment ${ }^{1,31,33}$ The unchanged inter-planer spacing observed in HRTEM and XRD data clearly indicates that surface treatment does not result in any noticeable change of the surface ligands. Therefore, similar to the previous reported surface treatment of $\mathrm{CsPbBr}_{3} \mathrm{NCs}^{30}$, ${ }^{38}$, the $\mathrm{Y}-\mathrm{Cl}$ ion pairs in our case only access the limited sites on the NC surface (defect sites) and do not strip the native capping ligands.

To confirm the surface modulation upon $\mathrm{YCl}_{3}$ treatment, $\mathrm{X}$-ray photoelectron spectroscopy (XPS) was conducted for as-synthesized, and $\mathrm{YCl}_{3}$-surface treated $\mathrm{CsPbCl}_{3} \mathrm{NCs}$. Figure 1e represents the XPS spectra for the Cs-4 $\mathrm{p}_{3 / 2}$ and $\mathrm{Y}-3 \mathrm{~d}$ region for both pristine and passivated $\mathrm{CsPbCl}_{3} \mathrm{NCs}\left(\mathrm{Y}-3 \mathrm{~d}\right.$ of $\mathrm{YCl}_{3}$ salt is also given for comparison). For pristine $\mathrm{CsPbl}_{3} \mathrm{NCs}$, a single peak centered at $\sim 158.7 \mathrm{eV}$ corresponding to $\mathrm{Cs}-4 \mathrm{p}_{3 / 2}$ core level was observed. However, for $\mathrm{YCl}_{3}$ passivated $\mathrm{CsPbCl}_{3} \mathrm{NCs}$, a new peak at approximately $\sim 160.3 \mathrm{eV}$ was manifested. Interestingly, in the treated $\mathrm{CsPbCl}_{3} \mathrm{NCs}$, the $\mathrm{Y}-3 \mathrm{~d}_{3 / 2}$ component observed at $160.3 \mathrm{eV}$ is shifted to lower binding energy by $0.5 \mathrm{eV}$ compared to the $\mathrm{Y}-3 \mathrm{~d}_{3 / 2}$ component observed at $160.8 \mathrm{eV}$ in the pure $\mathrm{YCl}_{3}$ salt. ${ }^{39}$ This result indicates new bond formation with the yttrium elements. ${ }^{39}$ We attribute this effect to the filling of surface $\mathrm{Pb}-\mathrm{Cl}$ ion pair defect by a $\mathrm{Y}-\mathrm{Cl}$ ion pair, as indicated by DFT calculations (see below). Quantitative XPS analysis for $\mathrm{CsPbCl}_{3} \mathrm{NCs}$ indicates a $\mathrm{Cl} / \mathrm{Pb}$ ratio of $2.6 / 1$ for the untreated surface. However, following the yttrium salt treatment, this ratio increases to 3.2/1, which is attributed to the development of a Cl-rich surface. The new yttrium bond formation along with the increase in the $\mathrm{Cl} / \mathrm{Pb}$ ratio after $\mathrm{NC}$ treatment demonstrates the dualsurface passivation by $\mathrm{YCl}_{3}$. It should be noted that the XPS analysis shows no significant changes in the $\mathrm{Cs} 3 \mathrm{~d}, \mathrm{~Pb} 4 \mathrm{f}, \mathrm{Cl} 2 \mathrm{p}$ and $\mathrm{N}$ 1s core-level spectra for both samples as a $\mathrm{Y}-\mathrm{Cl}$ ion pair is filling the surface $\mathrm{Pb}-\mathrm{Cl}$ defects after $\mathrm{YCl}_{3}$ treatment. These results suggest that $\mathrm{YCl}_{3}$ is competently anchored on the surface, i.e., forms a new bond, fills the surface $\mathrm{Pb}-\mathrm{Cl}$ ion pair defects and heals the uncoordinated $\mathrm{Pb}$ atoms. 

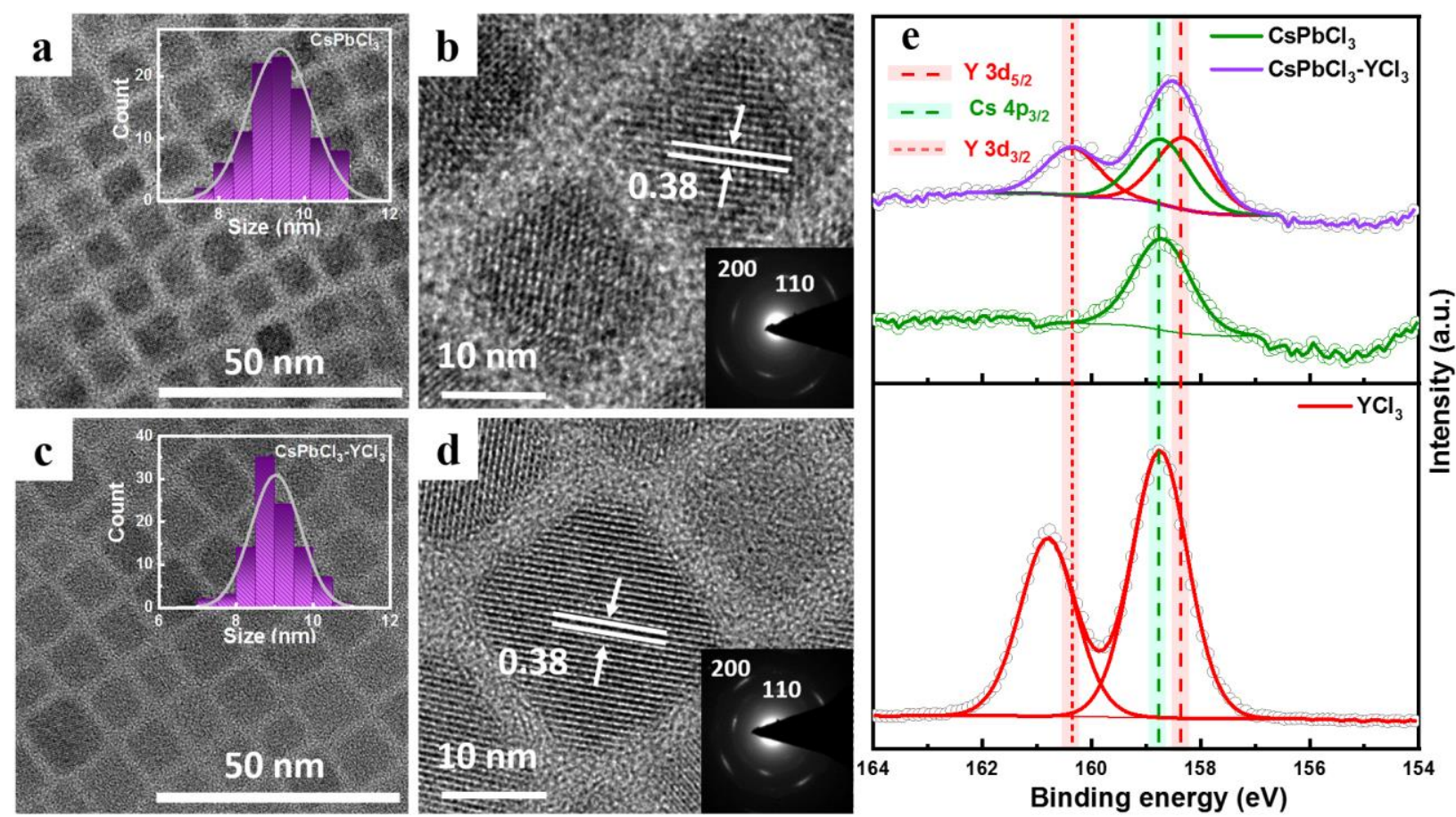

Figure 1. Representative TEM images of the $\mathrm{CsPbCl}_{3} \mathrm{NCs}$. The upper panel $(\mathrm{a}, \mathrm{b})$ shows low- and highresolution TEM images of pristine NCs. The lower panel (c,d) shows low- and high-resolution TEM images of the $\mathrm{YCl}_{3}$-treated NCs. Insets in $(b, \mathrm{~d})$ show the Selected Area Electron Diffraction (SAED) patterns for both pristine and passivated NCs. Insets in (a, c) show the size-distribution histograms for both pristine and passivated NCs. (e) XPS spectra for the Cs $4 \mathrm{P}_{3 / 2} / \mathrm{Y} 3 \mathrm{~d}$ region for both pristine and passivated $\mathrm{CsPbCl}_{3} \mathrm{NCs}$ compared with the $\mathrm{Y} 3 \mathrm{~d}$ core level spectrum of the pure $\mathrm{YCl}_{3}$ salt.

To study the impact of surface passivation on the physical properties of the NCs, the absorption and PL spectra were recorded for the samples before and after surface treatment. As shown in Figure 2a, the as-synthesized pristine $\mathrm{CsPbCl}_{3} \mathrm{NCs}$ exhibit sharp excitonic absorption and emission peaks at $394 \mathrm{~nm}$ and $404 \mathrm{~nm}$, respectively. Following the $\mathrm{YCl}_{3}$ treatment, a red shift of less than $1 \mathrm{~nm}$ in the emission peak is observed. Also, both pristine and the treated NCs exhibit narrow PL emission with linewidths of $11 \mathrm{~nm}$, confirming the high uniformity of the NCs. Remarkably, a $\sim 60$-fold enhancement in the PL intensity is observed following the $\mathrm{YCl}_{3}$ treatment. This significant improvement is providing clear experimental evidence for the removal of surface defects of NCs, see (Figure S3, S4). ${ }^{17,30,37-38}$ 
To support the dual-surface treatment by $\mathrm{YCl}_{3}$, we have examined the effect of $\mathrm{Y}$-acetate salt on the $\mathrm{CsPbCl}_{3} \mathrm{NC}$ surface, Figure 2b. Remarkably, we have found that the optical properties of the NCs were improved to some extent due to the steric hindrance effect preventing the direct binding of the Y-acetate to the surface of the NCs. Thus, this finding highlights the necessity of the presence of the trivalent metal chloride ions for better passivated surface defects and improved optical properties. To explore the impact of the surface treatment on the colloidal stability, a photostability test is conducted, which shows that the PL intensity of pristine NCs is quenched by up to $30 \%$ after two weeks. In contrast, the $\mathrm{YCl}_{3}$-treated NCs can maintain almost $100 \%$ of their original PL intensity during the entire 14 days. This study confirms that $\mathrm{YCl}_{3}$ not only removes the defects or the related surface traps, but also improves the durability of the PL properties Figure 2c.

To further investigate the surface treatment effect of other trivalent ions, we treated the assynthesized $\mathrm{CsPbCl}_{3} \mathrm{NCs}$ with different trivalent metal-chloride salts such as $\mathrm{InCl}_{3}, \mathrm{LaCl}_{3}, \mathrm{GdCl}_{3}$, and $\mathrm{YbCl}_{3}$. Interestingly, although the other trivalent ions also lead to an improvement in the optical properties of the NCs, the Y was most efficient in improving the PLQY as well as ensuring the stability of the NCs, Figure S5. We have also studied the surface treatment effect on $\mathrm{CsPbl}_{3} \mathrm{NCs}$ utilizing monovalent and divalent ions such as $\mathrm{Na}, \mathrm{Zn}$, and $\mathrm{Cd}$; however, none of them were comparatively effective, Figure S6. These findings underscore the high affinity of trivalent ions towards the surface of $\mathrm{CsPbl}_{3} \mathrm{NCs}$ by introducing more chloride ions to the surface. 

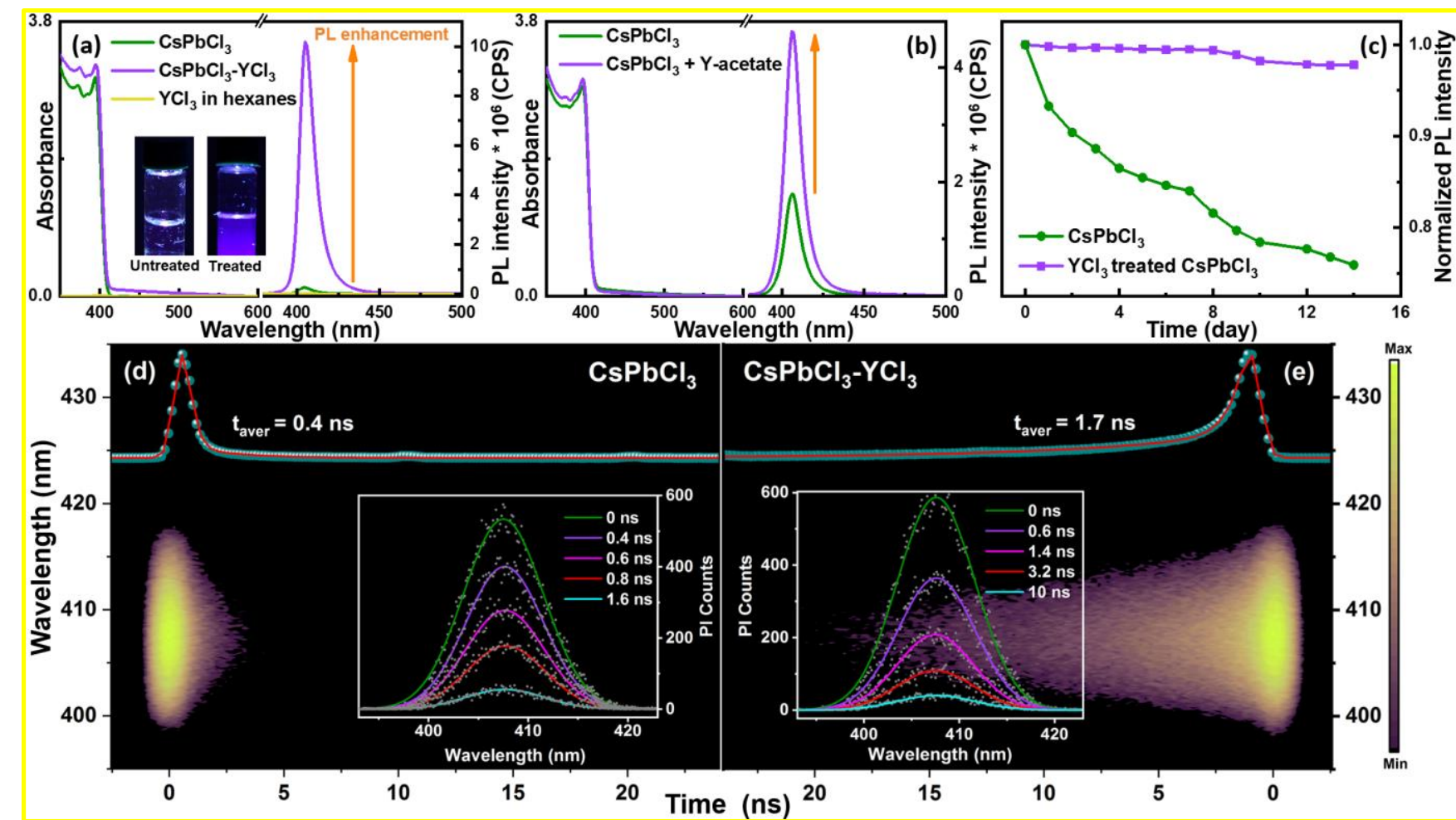

Figure 2. (a) Steady-state optical absorption and PL spectra for the as-synthesized $\mathrm{CsPbCl}_{3} \mathrm{NCs}$ dispersed in hexanes before and after $\mathrm{YCl}_{3}$ surface passivation, insets are photographs of the untreated and $\mathrm{YCl}_{3}$ treated NCs under 365-nm UV illumination. (b) Steady-state absorption and the relative PL spectrum for both pristine and yttrium acetate treated NCs. (c) The relative stability test represented by the normalized PL Intensity as a function of time (day) for pristine $\mathrm{NCs}$ and $\mathrm{YCl}_{3}$ passivated $\mathrm{NCs}$ after exposure to ambient conditions. The PL spectrum obtained upon 365-nm excitation. (d, e) Time-resolved $\mathrm{PL}$ decay traces (cyan) and the relative kinetic fitting (red) of pristine $\mathrm{CsPbCl}_{3} \mathrm{NCs}_{\text {s }}$ and $\mathrm{YCl}_{3}$ passivated NCs obtained using a streak camera and optical excitation at a wavelength of $390 \mathrm{~nm}$. The decay curves are displayed in the 0-25 ns time window. Insets show the transient PL spectra at different time delays before and after treatment, as indicated in the figure.

It has been lately demonstrated that doping impurity ions inside perovskite $\mathrm{NC}$ lattice can be considered as an efficient way to remove the intrinsic defects as well as the structural defects such as chloride and lead vacancies as a result enhance the optical properties the NCs. ${ }^{35,40}$ Therefore, we were also interested to try the doping strategy of $\mathrm{YCl}_{3}$ ions, aiming to increase the PLQY more than $60 \%$ by targeting the intrinsic defects in $\mathrm{CsPbCl}_{3} \mathrm{NCs}$. Accordingly, three different concentrations of $\mathrm{YCl}_{3}(1 \%$, 
$5 \%$, and $10 \%$ ) have been doped inside the $\mathrm{CsPbl}_{3}$ lattice during the synthesis. However, we could not observe much improvement in the PLQY as was achieved by the post-synthetic treatment method. The PLQY of the doped NCs was approximately 3-5\%, even after applying the same surface passivation conditions to the surface a PLQY of only $25 \%$ was achieved. This may be due to the mismatch in the 6coordinate ionic radii of $\mathrm{Y}(90 \mathrm{pm})$ and $\mathrm{Pb}(119 \mathrm{pm})$. These results again highlight the significant influence of the surface defects in $\mathrm{CsPbCl}_{3} \mathrm{NCs}$ compared to the bulk, Figure S7-S9.

It is well known that the existence of trap states on the $\mathrm{NC}$ surface, increases the non-radiative surface states, which leads to a shortening of the lifetime. Thus, passivating the surface defects of the NCs would have a substantial influence on the charge carrier lifetime, and, accordingly, lead to prolonging the excited-state lifetime. For this purpose, time-resolved PL spectroscopy was conducted using a streak camera with picosecond resolution, Figure 2 (d, e). The time-resolved PL decay curves measured for as-prepared NCs were fitted with bi-exponential decay functions. The short and long-lived PL lifetime components and the relative amplitudes (\%) are listed in Table S1. The radiative and nonradiative decay rates were estimated from the PLQYs, with the corresponding average PL decay times presented in Table S2. The significant increase in the average PL decay lifetime from 0.4 to $1.7 \mathrm{~ns}$, after $\mathrm{YCl}_{3}$ treatment, indicates absolute surface state passivation. Our average lifetime results are consistent and slightly longer than the reported lifetimes for $\mathrm{CsPbCl}_{3} \mathrm{NCs} .{ }^{38}$ Also, we observed that the nonradiative decay rates which were estimated from the PLQYs as well as the fitted lifetimes are very consistent and; are reduced from $2.475 \mathrm{~ns}^{-1}$ to $0.236 \mathrm{~ns}^{-1}$ after surface treatment (Table S1, S2). These findings imply that our $\mathrm{YCl}_{3}$-treated samples successfully suppress the formation of non-radiative recombination centers on the surface of the $\mathrm{CsPbCl}_{3} \mathrm{NCs}^{41-44}$ 

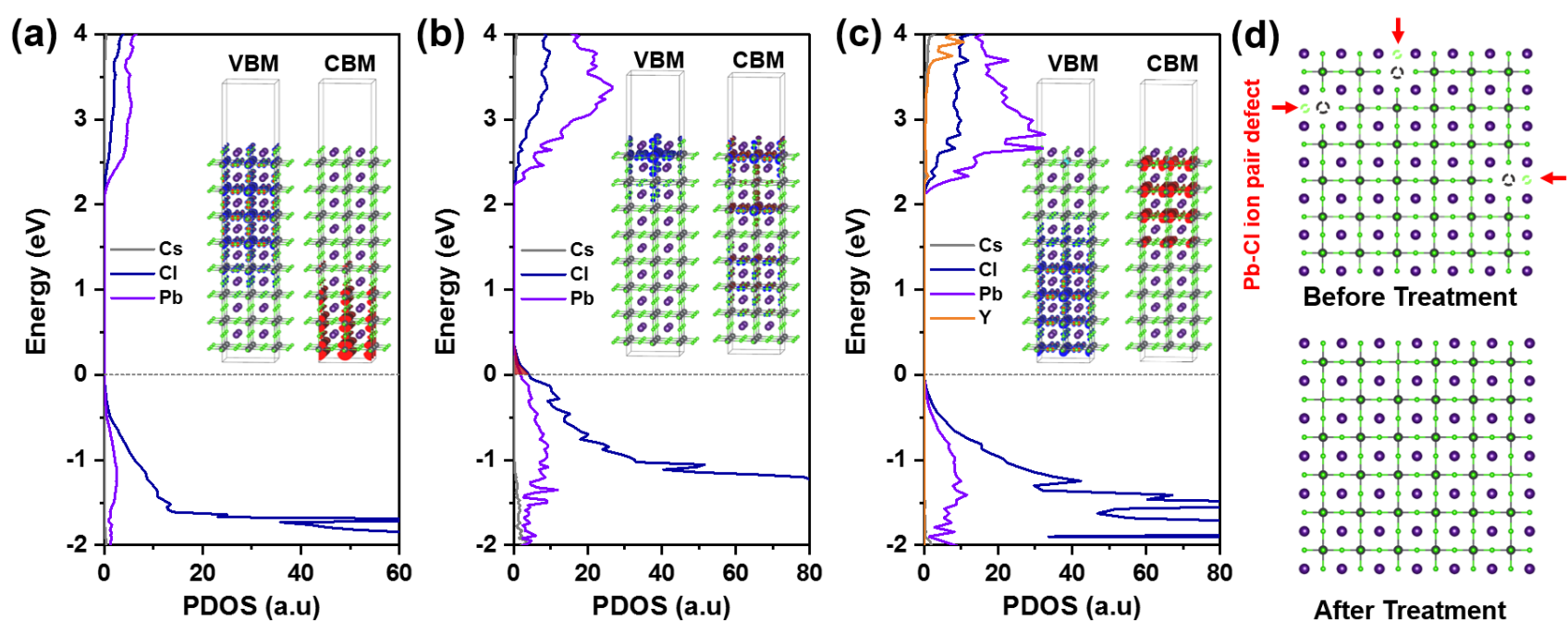

Figure 3. Projected density of states and electronic charge density for the VBM and CBM for (a) ideal $\mathrm{CsPbCl}_{3}$ slab, (b) with a removed $\mathrm{Pb}-\mathrm{Cl}$ ion pair, and (c) with a filled $\mathrm{Y}-\mathrm{Cl}$ ion pair; (d) Schematic representation of the crystal structure of $\mathrm{CsPbCl}_{3} \mathrm{NCs}$ and the mechanism proposed for the $\mathrm{YCl}_{3}$ surface treatment.

We performed DFT calculations to understand the mechanism of PL enhancement after surface treatment using $\mathrm{YCl}_{3}$. In the wet-chemistry synthesis of $\mathrm{CsPCl}_{3} \mathrm{NCs}$, the surface traps are unavoidably formed due to the appearance of non-passivated sites (like a $\mathrm{Pb}-\mathrm{Cl}$ ion pair defect), which can become non-radiative centers that can degrade the optical performance. Based on this mechanism, we considered three models as given in Figure 3: a) ideal $\mathrm{CsPCl}_{3}$ surface, b) with a removed $\mathrm{Pb}-\mathrm{Cl}$ ion pair on the surface (note that such imperfect surface with a missing $\mathrm{Pb}-\mathrm{Cl}$ ion pair can follow the chemical equilibrium that all the $\mathrm{Pb}$ atoms are six-coordinated with $\mathrm{Cl}$ atoms on the surface); and c) treatment with a filled $\mathrm{Y}-\mathrm{Cl}$ ion pair at the surface. In the ideal $\mathrm{CsPCl}_{3}$ slab, the hole and electron wave function distribution are separated well due to CsCl-rich surface termination, where the holes are delocalized on the top layers and electrons are delocalized in the bulk. The $\mathrm{Pb}-\mathrm{Cl}$ ion pair defect leads to the formation of a trap state above the conduction band (highlighted in red area), and holes that are highly localized on the top surface layer, which acts as a hole-trapping center. Interestingly, once the removed $\mathrm{Pb}-\mathrm{Cl}$ ion pair on the surface is occupied by the $\mathrm{Y}-\mathrm{Cl}$ ion pair, they do not create any new mid-gap states but enrich the density of 
calculations were conducted assuming that the noise current is primarily dominated by the shot noise. ${ }^{48}$ The decrease in responsivity versus the increase in power density (Figure 4e) was ascribed to the filling of the trap states, which provide higher photoconductivity at low power densities. ${ }^{49}$ The effect of surface passivation was further highlighted by $40 \%$ reduction in the rise of the temporal photoresponse of treated versus non-treated NCs (see Figures $4 \mathbf{f}$ and S10d).

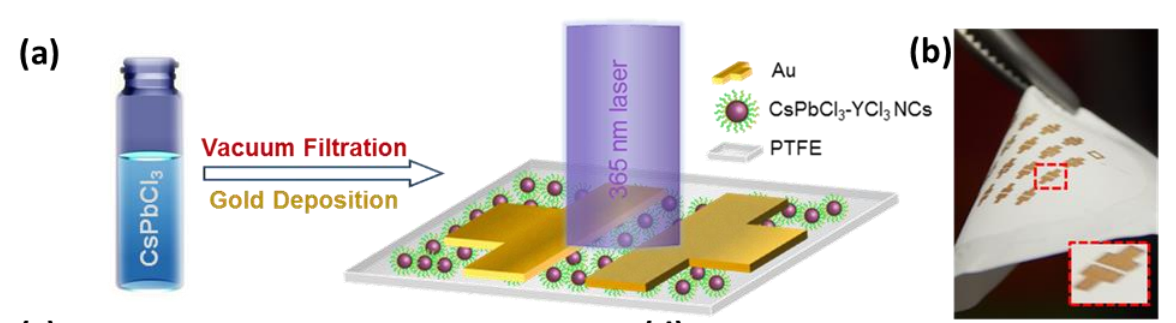

(c)

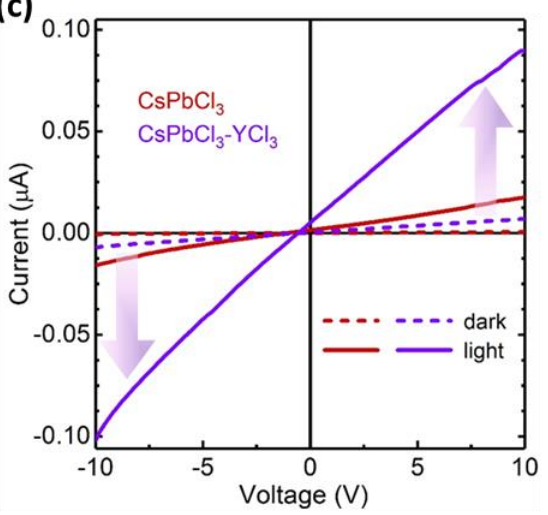

(e)

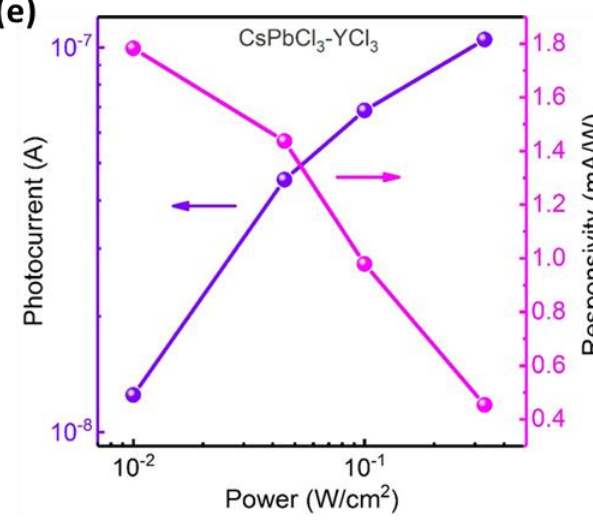

(d)

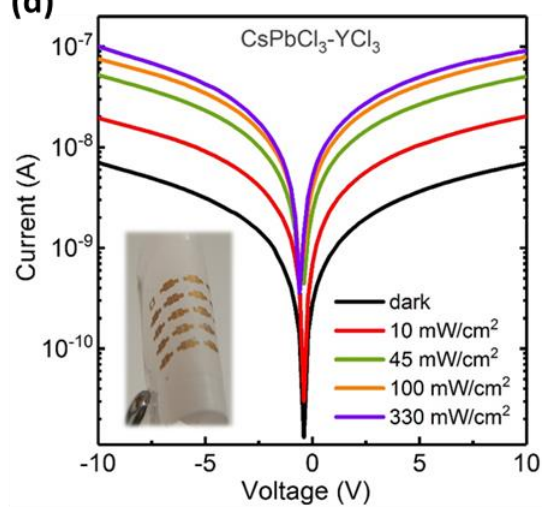

(f)

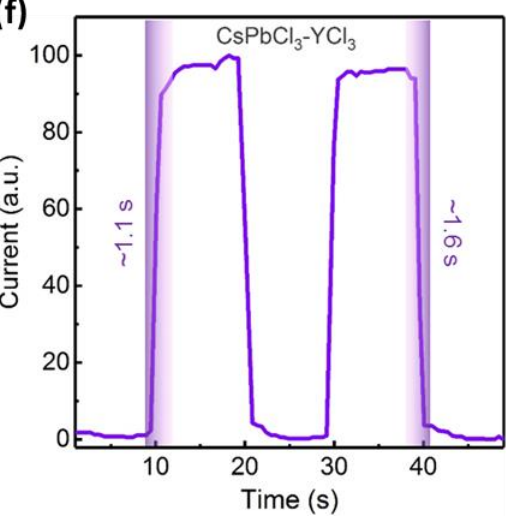

Figure 4. (a) Schematic illustration of the device fabrication and photoelectric measurements for a $\mathrm{CsPCl}_{3}$ single cell. (b) Photograph of an array of two-terminal, lateral-type thin film $\mathrm{CsPbCl}_{3}$ devices on a PTFE flexible membrane. Inset: Magnified photograph of a single cell. (c) Linear scale $I-V$ characteristics for $\mathrm{YCl}_{3}$-treated (violet) and non-treated $\mathrm{CsPCl}_{3}$ (magenta) devices before (dashed lines) 
and after (solid lines) UV (365 nm) light illumination at a power density of $330 \mathrm{~mW} / \mathrm{cm}^{2}$. All devices are kept under a bias voltage of $\pm 10 \mathrm{~V}$. (d) Semi-log scale $I$ - $V$ curves for $\mathrm{YCl}_{3}$-treated $\mathrm{CsPbl}_{3}$ under UV illumination at different power densities. Inset: Photograph of a rolled $\mathrm{CsPCl}_{3}-\mathrm{YCl}_{3}$ film with several cells. (e) Photocurrent (left) and responsivity (right) at $-10 \mathrm{~V}$ as a function of UV power density. (f) Temporal photoresponse of $\mathrm{CsPCl}_{3}-\mathrm{YCl}_{3}$ under alternating dark and $\mathrm{UV}$ illumination.

In conclusion, we demonstrate how a simultaneous dual-surface passivation approach using Y and $\mathrm{Cl}$ ions can significantly improve not only the emission properties, but also the surface stability of $\mathrm{CsPbl}_{3} \mathrm{NCs}$. Our results suggest that $\mathrm{YCl}_{3}$ can robustly fill the $\mathrm{Pb}-\mathrm{Cl}$ ion pair defects and passive the uncoordinated $\mathrm{Pb}$ atoms on the NC surface, enhancing the PLQY by 60 times compared to untreated samples. We were also studied the photoelectric response of $\mathrm{CsPbCl}_{3}$ thin films before and after $\mathrm{YCl}_{3}$ treatment, with the results showing a noticeable photocurrent enhancement after treatment. These results unravel the underlying mechanism behind the low PLQY of $\mathrm{CsPbCl}_{3} \mathrm{NCs}$ and highlight the enormous impact of the surface defects on $\mathrm{CsPbCl}_{3} \mathrm{NCs}$. Such findings highlight the potential for $\mathrm{CsPbl}_{3} \mathrm{NCs}$ to be utilized as efficient blue-emitters for a range of optoelectronic applications.

\section{ASSOCIATED CONTENT}

Additional experimental results including: (experimental and characterization sections, XRD, XPS, Quantum Yield, steady-state of trivalent and monovalent metal ions, steady-state of the doping effect, average lifetime and radiative and non-radiative rates extracted, $\mathrm{I}-\mathrm{V}$ curve of pristine $\mathrm{CsPbl}_{3}$ ) are provided in the supporting information.

\section{AUTHOR INFORMATION}

\section{*Email: omar.abdelsaboor@kaust.edu.sa}

\section{Notes}

The authors declare no competing financial interest.

\section{ACKNOWLEDGMENT}

The authors acknowledge funding support from KAUST. 


\section{REFERENCES}

(1) Protesescu, L.; Yakunin, S.; Bodnarchuk, M. I.; Krieg, F.; Caputo, R.; Hendon, C. H.; Yang, R. X.; Walsh, A.; Kovalenko, M. V. Nanocrystals of Cesium Lead Halide Perovskites $\left(\mathrm{CsPbX}_{3}, \mathrm{X}=\mathrm{Cl}, \mathrm{Br}\right.$, and I): Novel Optoelectronic Materials Showing Bright Emission with Wide Color Gamut. Nano Lett. 2015, 15, 3692-3696.

(2) Du, X.; Wu, G.; Cheng, J.; Dang, H.; Ma, K.; Zhang, Y.-W.; Tan, P.-F.; Chen, S. High-Quality $\mathrm{CsPbBr}_{3}$ Perovskite Nanocrystals for Quantum Dot Light-Emitting Diodes. RSC Adv. 2017, 7, 1039110396.

(3) Zhang, X.; Lin, H.; Huang, H.; Reckmeier, C.; Zhang, Y.; Choy, W. C. H.; Rogach, A. L. Enhancing the Brightness of Cesium Lead Halide Perovskite Nanocrystal Based Green Light-Emitting Devices through the Interface Engineering with Perfluorinated Ionomer. Nano Lett. 2016, 16, 1415 1420.

(4) Stranks, S. D.; Snaith, H. J. Metal-Halide Perovskites for Photovoltaic and Light-Emitting Devices. Nat. Nanotechn. 2015, 10, 391.

(5) Yakunin, S.; Protesescu, L.; Krieg, F.; Bodnarchuk, M. I.; Nedelcu, G.; Humer, M.; De Luca, G.; Fiebig, M.; Heiss, W.; Kovalenko, M. V. Low-Threshold Amplified Spontaneous Emission and Lasing from Colloidal Nanocrystals of Caesium Lead Halide Perovskites. Nat. Commun. 2015, 6, 8056.

(6) Eaton, S. W.; Lai, M.; Gibson, N. A.; Wong, A. B.; Dou, L.; Ma, J.; Wang, L.-W.; Leone, S. R.; Yang, P. Lasing in Robust Cesium Lead Halide Perovskite Nanowires. Proc. Natl. Acad. Sci. U.S.A. 2016, 113, 1993-1998.

(7) Xing, G.; Mathews, N.; Lim, S. S.; Yantara, N.; Liu, X.; Sabba, D.; Grätzel, M.; Mhaisalkar, S.; Sum, T. C. Low-Temperature Solution-Processed Wavelength-Tunable Perovskites for Lasing. Nat. Mater. 2014, 13, 476.

(8) Dursun, I.; Zheng, Y.; Guo, T.; De Bastiani, M.; Turedi, B.; Sinatra, L.; Haque, M. A.; Sun, B.; Zhumekenov, A. A.; Saidaminov, M. I.; et al. Efficient Photon Recycling and Radiation Trapping in Cesium Lead Halide Perovskite Waveguides. ACS Energy Lett. 2018, 3, 1492-1498.

(9) Tong, X.-W.; Kong, W.-Y.; Wang, Y.-Y.; Zhu, J.-M.; Luo, L.-B.; Wang, Z.-H. HighPerformance Red-Light Photodetector Based on Lead-Free Bismuth Halide Perovskite Film. ACS Appl. Mater. Interfaces 2017, 9 , 18977-18985.

(10) Gui, P.; Chen, Z.; Li, B.; Yao, F.; Zheng, X.; Lin, Q.; Fang, G. High-Performance Photodetectors Based on Single All-Inorganic $\mathrm{CsPbBr}_{3}$ Perovskite Microwire. ACS Photonics 2018, 5, 2113-2119.

(11) Lv, L.; Xu, Y.; Fang, H.; Luo, W.; Xu, F.; Liu, L.; Wang, B.; Zhang, X.; Yang, D.; Hu, W.; et al. Generalized Colloidal Synthesis of High-Quality, Two-Dimensional Cesium Lead Halide Perovskite Nanosheets and their Applications in Photodetectors. Nanoscale 2016, 8, 13589-13596.

(12) Ramasamy, P.; Lim, D.-H.; Kim, B.; Lee, S.-H.; Lee, M.-S.; Lee, J.-S. All-Inorganic Cesium Lead Halide Perovskite Nanocrystals for Photodetector Applications. Chem. Commun. 2016, 52, 20672070. 
(13) Dou, L.; Yang, Y.; You, J.; Hong, Z.; Chang, W.-H.; Li, G.; Yang, Y. Solution-Processed Hybrid Perovskite Photodetectors with High Detectivity. Nat. Commun. 2014, 5, 5404.

(14) Zhuo, S.; Zhang, J.; Shi, Y.; Huang, Y.; Zhang, B. Self-Template-Directed Synthesis of Porous Perovskite Nanowires at Room Temperature for High-Performance Visible-Light Photodetectors. Angew. Chem. Int. Ed. 2015, 54, 5693-5696.

(15) Maculan, G.; Sheikh, A. D.; Abdelhady, A. L.; Saidaminov, M. I.; Haque, M. A.; Murali, B.; Alarousu, E.; Mohammed, O. F.; Wu, T.; Bakr, O. M. $\mathrm{CH}_{3} \mathrm{NH}_{3} \mathrm{PbCl}_{3}$ Single Crystals: Inverse Temperature Crystallization and Visible-Blind UV-Photodetector. J. Phys. Chem. Lett. 2015, 6, 37813786.

(16) Di Stasio, F.; Christodoulou, S.; Huo, N.; Konstantatos, G. Near-Unity Photoluminescence Quantum Yield in $\mathrm{CsPbBr}_{3}$ Nanocrystal Solid-State Films via Postsynthesis Treatment with Lead Bromide. Chem. Mater. 2017, 29, 7663-7667.

(17) Pan, J.; Shang, Y.; Yin, J.; De Bastiani, M.; Peng, W.; Dursun, I.; Sinatra, L.; El-Zohry, A. M.; Hedhili, M. N.; Emwas, A.-H.; et al. Bidentate Ligand-Passivated $\mathrm{CsPbI}_{3}$ Perovskite Nanocrystals for Stable Near-Unity Photoluminescence Quantum Yield and Efficient Red Light-Emitting Diodes. J. Am. Chem. Soc. 2018, 140, 562-565.

(18) Tong, Y.; Bladt, E.; Aygüler, M. F.; Manzi, A.; Milowska, K. Z.; Hintermayr, V. A.; Docampo, P.; Bals, S.; Urban, A. S.; Polavarapu, L.; Feldmann, J. Highly Luminescent Cesium Lead Halide Perovskite Nanocrystals with Tunable Composition and Thickness by Ultrasonication. Angew. Chem. Int. Ed. 2016, 55, 13887-13892.

(19) Huang, H.; Polavarapu, L.; Sichert, J. A.; Susha, A. S.; Urban, A. S.; Rogach, A. L. Colloidal Lead Halide Perovskite Nanocrystals: Synthesis, Optical Properties and Applications. Npg Asia Mater. 2016, 8, e328.

(20) Su, Y.; Chen, X.; Ji, W.; Zeng, Q.; Ren, Z.; Su, Z.; Liu, L. Highly Controllable and Efficient Synthesis of Mixed-Halide $\mathrm{CsPbX}_{3}(\mathrm{X}=\mathrm{Cl}, \mathrm{Br}, \mathrm{I})$ Perovskite QDs toward the Tunability of Entire Visible Light. ACS Appl. Mater. Interfaces 2017, 9, 33020-33028.

(21) Peng, L.; Dutta, A.; Xie, R.; Yang, W.; Pradhan, N. Dot-Wire-Platelet-Cube: Step Growth and Structural Transformations in $\mathrm{CsPbr}_{3}$ Perovskite Nanocrystals. ACS Energy Lett. 2018, 2014-2020.

(22) Ravi, V. K.; Scheidt, R. A.; Nag, A.; Kuno, M.; Kamat, P. V. To Exchange or Not to Exchange. Suppressing Anion Exchange in Cesium Lead Halide Perovskites with $\mathrm{PbSO}_{4}-$ Oleate Capping. ACS Energy Lett. 2018, 3, 1049-1055.

(23) Huang, H.; Bodnarchuk, M. I.; Kershaw, S. V.; Kovalenko, M. V.; Rogach, A. L. Lead Halide Perovskite Nanocrystals in the Research Spotlight: Stability and Defect Tolerance. ACS Energy Lett. 2017, 2, 2071-2083.

(24) Begum, R.; Parida, M. R.; Abdelhady, A. L.; Murali, B.; Alyami, N. M.; Ahmed, G. H.; Hedhili, M. N.; Bakr, O. M.; Mohammed, O. F. Engineering Interfacial Charge Transfer in $\mathrm{CsPbBr}_{3}$ Perovskite Nanocrystals by Heterovalent Doping. J. Am. Chem. Soc. 2017, 139, 731-737. 
(25) Ahmed, G. H.; Liu, J.; Parida, M. R.; Murali, B.; Bose, R.; AlYami, N. M.; Hedhili, M. N.; Peng, W.; Pan, J.; Besong, T. M. D.; et al. Shape-Tunable Charge Carrier Dynamics at the Interfaces between Perovskite Nanocrystals and Molecular Acceptors. J. Phys. Chem. Lett. 2016, 7, 3913-3919.

(26) Yang, H.; Zhang, Y.; Pan, J.; Yin, J.; Bakr, O. M.; Mohammed, O. F. Room-Temperature Engineering of All-Inorganic Perovskite Nanocrsytals with Different Dimensionalities. Chem. Mater. 2017, 29, 8978-8982.

(27) Ahmed, G. H.; Yin, J.; Bose, R.; Sinatra, L.; Alarousu, E.; Yengel, E.; AlYami, N. M.; Saidaminov, M. I.; Zhang, Y.; Hedhili, M. N.; et al. Pyridine-Induced Dimensionality Change in Hybrid Perovskite Nanocrystals. Chem. Mater. 2017, 29, 4393-4400.

(28) Ten Brinck, S.; Infante, I. Surface Termination, Morphology, and Bright Photoluminescence of Cesium Lead Halide Perovskite Nanocrystals. ACS Energy Lett. 2016, 1, 1266-1272.

(29) Brennan, M. C.; Draguta, S.; Kamat, P. V.; Kuno, M. Light-Induced Anion Phase Segregation in Mixed Halide Perovskites. ACS Energy Lett. 2018, 3, 204-213.

(30) Koscher, B. A.; Swabeck, J. K.; Bronstein, N. D.; Alivisatos, A. P. Essentially Trap-Free CsPbBr3 Colloidal Nanocrystals by Postsynthetic Thiocyanate Surface Treatment. J. Am. Chem. Soc. 2017, 139, 6566-6569.

(31) Imran, M.; Caligiuri, V.; Wang, M.; Goldoni, L.; Prato, M.; Krahne, R.; De Trizio, L.; Manna, L. Benzoyl Halides as Alternative Precursors for the Colloidal Synthesis of Lead-Based Halide Perovskite Nanocrystals. J. Am. Chem. Soc. 2018, 140, 2656-2664.

(32) Liu, H.; Wu, Z.; Shao, J.; Yao, D.; Gao, H.; Liu, Y.; Yu, W.; Zhang, H.; Yang, B. CsPb $\mathrm{Mn}_{1-}$ ${ }_{x} \mathrm{Cl}_{3}$ Perovskite Quantum Dots with High Mn Substitution Ratio. ACS Nano 2017, 11, 2239-2247.

(33) Mir, W. J.; Jagadeeswararao, M.; Das, S.; Nag, A. Colloidal Mn-Doped Cesium Lead Halide Perovskite Nanoplatelets. ACS Energy Lett. 2017, 2, 537-543.

(34) Parobek, D.; Roman, B. J.; Dong, Y.; Jin, H.; Lee, E.; Sheldon, M.; Son, D. H. Exciton-to-Dopant Energy Transfer in Mn-Doped Cesium Lead Halide Perovskite Nanocrystals. Nano Lett. 2016, 16, 73767380 .

(35) Yong, Z.-J.; Guo, S.-Q.; Ma, J.-P.; Zhang, J.-Y.; Li, Z.-Y.; Chen, Y.-M.; Zhang, B.-B.; Zhou, Y.; Shu, J.; Gu, J.-L.; et al. Doping-Enhanced Short-Range Order of Perovskite Nanocrystals for Near-Unity Violet Luminescence Quantum Yield. J. Am. Chem. Soc. 2018, 140, 9942-9951.

(36) Jun, P.; Na, Q. L.; Yongbiao, Z.; Wei, P.; Banavoth, M.; P., S. S.; Mingjian, Y.; Lutfan, S.; M., A. N.; Jiakai, L.; Emre, Y.; et al. Highly Efficient Perovskite-Quantum-Dot Light-Emitting Diodes by Surface Engineering. Adv. Mater. 2016, 28, 8718-8725.

(37) Pan, J.; Sarmah, S. P.; Murali, B.; Dursun, I.; Peng, W.; Parida, M. R.; Liu, J.; Sinatra, L.; Alyami, N.; Zhao, C.; et al. Mohammed, O. F. Air-Stable Surface-Passivated Perovskite Quantum Dots for UltraRobust, Single- and Two-Photon-Induced Amplified Spontaneous Emission. J. Phys. Chem. Lett. 2015, 6, 5027-5033. 
(38) Ahmed, T.; Seth, S.; Samanta, A. Boosting the Photoluminescence of $\mathrm{CsPbX}_{3}(\mathrm{X}=\mathrm{Cl}, \mathrm{Br}, \mathrm{I})$ Perovskite Nanocrystals Covering a Wide Wavelength Range by Postsynthetic Treatment with Tetrafluoroborate Salts. Chem. Mater. 2018, 30, 3633-3637.

(39) Minghua, L.; Yahuan, H.; Xiaoqin, Y.; Zhuo, K.; Yan, G.; Yong, L.; Xinqin, L.; Ruxiao, Z.; Yue, Z. Efficient Yttrium(III) Chloride-Treated $\mathrm{TiO}_{2}$ Electron Transfer Layers for Performance-Improved and Hysteresis-Less Perovskite Solar Cells. ChemSusChem 2018, 11, 171-177.

(40) Yao, J.-S.; Ge, J.; Han, B.-N.; Wang, K.-H.; Yao, H.-B.; Yu, H.-L.; Li, J.-H.; Zhu, B.-S.; Song, J.-Z.; Chen, C.; et al. $\mathrm{Ce}^{3+}$-Doping to Modulate Photoluminescence Kinetics for Efficient $\mathrm{CsPbBr}_{3}$ Nanocrystals Based Light-Emitting Diodes. J. Am. Chem. Soc.2018, 140, 3626-3634.

(41) Abdellah, M.; Karki, K. J.; Lenngren, N.; Zheng, K.; Pascher, T.; Yartsev, A.; Pullerits, T. Ultra Long-Lived Radiative Trap States in CdSe Quantum Dots. J. Phys. Chem. C 2014, 118, 21682-21686.

(42) Cohn, A. W.; Schimpf, A. M.; Gunthardt, C. E.; Gamelin, D. R. Size-Dependent Trap-Assisted Auger Recombination in Semiconductor Nanocrystals. Nano Lett. 2013, 13, 1810-1815.

(43) Jones, M.; Lo, S. S.; Scholes, G. D. Quantitative Modeling of the Role of Surface Traps in CdSe/CdS/ZnS Nanocrystal Photoluminescence Decay Dynamics. Proc. Natl. Acad. Sci. U.S.A. 2009, 106, 3011-3016.

(44) Zheng, K.; Žídek, K.; Abdellah, M.; Messing, M. E.; Al-Marri, M. J.; Pullerits, T. Trap States and Their Dynamics in Organometal Halide Perovskite Nanoparticles and Bulk Crystals. J. Phys. Chem. C 2016, 120, 3077-3084.

(45) G., G. H., Photoelectronic Properties of Semiconductors. By Richard H. Bube, Cambridge University Press, Cambridge 1992, 318 pp., ISBN 0-521-40681-1. Adv. Mater. 1993, 5, 65-66.

(46) Leijtens, T.; Eperon, G. E.; Barker, A. J.; Grancini, G.; Zhang, W.; Ball, J. M.; Kandada, A. R. S.; Snaith, H. J.; Petrozza, A. Carrier Trapping and Recombination: The Role of Defect Physics in Enhancing the Open Circuit Voltage of Metal Halide Perovskite Solar Cells. Energy Environ. Sci 2016, 9, 3472-3481.

(47) Cha, J.-H.; Han, J. H.; Yin, W.; Park, C.; Park, Y.; Ahn, T. K.; Cho, J. H.; Jung, D.-Y. Photoresponse of $\mathrm{CsPbBr}_{3}$ and $\mathrm{Cs}_{4} \mathrm{PbBr}_{6}$ Perovskite Single Crystals. J. Phys. Chem. Lett. 2017, 8, $565-$ 570 .

(48) Velusamy, D. B.; Haque, M. A.; Parida, M. R.; Zhang, F.; Wu, T.; Mohammed, O. F.; Alshareef, H. N. 2D Organic-Inorganic Hybrid Thin Films for Flexible UV-Visible Photodetectors. Adv. Funct. Mater. 2017, 27, 1605554.

(49) Konstantatos, G., Sargent, E. Colloidal Quantum Dot Optoelectronics and Photovoltaics. Cambridge University Press: Cambridge, 2013. Doi:10.1017/CBO9781139022750 